\title{
Cost-benefit analysis of outsourcing cleaning services at Mahalapye hospital, Botswana
}

\author{
Jonathan Cali ${ }^{1}$, Heather A. Cogswell ${ }^{1}$, Mompati Buzwani ${ }^{2}$, Elizabeth Ohadi ${ }^{1}$, Carlos Avila*1 \\ ${ }^{1}$ Abt Associates, Montgomery Ave, Bethesda MD, United States \\ ${ }^{2}$ Ministry of Health Botswana, Private Bag, Gaborone, Botswana
}

Received: July 29, 2015

DOI: $10.5430 /$ jha.v5n1p114
Accepted: November 5, $2015 \quad$ Online Published: December 10, 2015

URL: http://dx.doi.org/10.5430/jha.v5n1p114

\begin{abstract}
Objective: As part of its national privatization strategy to diversify the economy, Botswana has started outsourcing nonclinical services at seven public hospitals. Hospital managers are signing contracts without knowing whether outsourcing offers better value for money than "insourcing". The objective of this study is to assist hospital administrators in making evidence-based outsourcing decisions.

Methods: We conducted a cost-benefit analysis of cleaning services at Mahalapye Hospital. We take the hospital manager's perspective when considering two alternatives: outsourcing, and "insourcing". We used an activity-based costing approach and monetised benefits by weighting costs of the alternatives based on a service quality survey of hospital managers.

Results: After adjusting per quality of the service, outsourcing provides greater value for money in terms of "cleanliness per pula spent" than insourcing. Incremental costs of outsourcing are Botswana Pula (BWP) 5 million (US \$524,135) over five years but outsourcing is cost-beneficial after considering quality. The benefit-cost ratio of 1.06 means that outsourcing would return six cents in value for every dollar invested, resulting in net gains for Mahalapye Hospital of BWP 1.7 million (US \$182,365) over five years.

Discussion: Important lessons for hospital managers include: 1) Assessing the value of outsourcing requires information on the unit price of the outsourced services; 2) Outsourcing can be more costly than insourcing; 3) Outsourcing may be justified if it increases the quality of the service; 4) Collaboration between hospitals and vendors could reduce costs and increase benefits for both vendor and purchaser; and 5) Outsourcing should get more cost-beneficial as vendors and hospitals gain experience working together.

Conclusions: The lessons from this study are relevant to other hospitals considering outsourcing agreements. Outsourcing requires managerial skills, supported by sound benchmark data and proper quality monitoring to streamline operations, achieve value for money and improve service delivery so hospitals can focus on core clinical services.
\end{abstract}

Key Words: Outsourcing, Cost-benefit, Non-clinical services, Botswana, Cleaning services, Hospital, Health care

\section{INTRODUCTION}

Botswana has experienced rapid economic growth in the decades since its independence in 1966, and is now classified as an upper-middle-income country, with a gross domestic product per capita of 7,200 U.S. dollars in 2014. ${ }^{[1]}$ This period of economic growth was primarily driven by the public sector, and was financed by a steady source of diamond revenues. As a result, the private sector in Botswana remained

\footnotetext{
*Correspondence: Carlos Avila; Email: Carlos_Avila@abtassoc.com; Address: Abt Associates, 4550 Montgomery Ave, Suite 800 North, Bethesda MD, 20814, United States.
} 
small, while the government grew to become the country's leading employer.

The Government of Botswana (GoB) is currently implementing a long-term strategy to diversify the economy, create opportunities for growth in the private sector, and increase the efficiency of the public sector. Outsourcing service delivery, a key privatization approach outlined in GoB policies, involves the "transfer of provision of services to the private sector with government retaining responsibility for ensuring the quality of the services and the efficiency with which the services are being delivered". [2] The Ministry of Health $(\mathrm{MoH})$ is participating in GoB's privatisation strategy by outsourcing some nonclinical services in its hospitals. These include laundry, catering services, cleaning, porter and grounds-maintenance services, and security services. Seven MoH hospitals around the country have already begun outsourcing, and others are considering outsourcing in the near future.

The most frequently-cited reasons for outsourcing include improving service delivery performance, improving quality of care, reducing costs, and increasing efficiency. ${ }^{[3-5]}$ In theory, specialised managers in the private sector would be able to reduce costs and introduce new technologies and methods for delivering services. Competition for tenders among private vendors would also drive down the cost of the service and encourage increases in efficiency ${ }^{[6]}$ Finally, economies of scale would allow private vendors to deliver services at lower costs than hospitals. ${ }^{[5,7]}$

Studies on outsourcing clinical services from Zimbabwe, South Arica, and Cambodia have demonstrated that contracted providers can deliver at lower unit costs than their public sector counterparts, while maintaining quality-indicating improvement in efficiency at the provider level. ${ }^{[3,8,9]}$ For example, experiences from Cambodia have shown that contracting out Reproductive Health/Family Planning services costs less and improves equity and access. ${ }^{[10]}$

The literature around outsourcing non-clinical services, however, is not definitive on whether contracting actually lowers the overall cost of service delivery and it has not yet been demonstrated that contracting out increases the efficiency of the overall health system. ${ }^{[3]}$ In Tunisia, several university teaching hospitals subcontracted their catering and cleaning services, resulting in better quality of services but at a higher price. ${ }^{[11]}$ The same was found in Jamaica, where contracting out cleaning and portering services resulted in 25 percent higher costs, but also in higher quality and increased scope. ${ }^{[6]}$ In the Czech Republic, outsourced hospital catering services were found to be cost-prohibitive, and the public hospital ended up resuming provision of catering services itself. ${ }^{[11]}$
Finally, a catering contract in India resulted in lower costs to the hospitals, but quality and quantity of food was worse. ${ }^{[9]}$

Hospital managers in Botswana have been signing outsourcing contracts without knowing whether outsourcing offers better value for money than the current insourcing system, in which hospitals provide the nonclinical services in-house. ${ }^{[12]}$ Therefore hospitals considering outsourcing lack the information needed to decide whether they should outsource, and how they should go about negotiating contracts with private vendors. The objective of this study is twofold: first, to analyse the costs and benefits of outsourcing cleaning services at Mahalapye Hospital using: (1) a benchmark cost of insourcing the service; (2) the cost of outsourcing the service to a private vendor; and (3) qualitative service quality assessments to determine changes in quality perceived by hospital management; second, to highlight important lessons that may assist hospital administrators in navigating the outsourcing process.

\section{METHODS}

\subsection{Setting}

Mahalapye Hospital is a modern 260-bed public district hospital located in the Central District of Botswana. Built in 2008, it has an annual operating budget of approximately Botswana pula (BWP) 24 million (US\$ 2.6 million), and a floor space of 28,461 square metres. It admits about 8,000 inpatients per year. The hospital began outsourcing security services in 2011, and laundry and cleaning services in April and May of 2014, respectively.

\subsection{Study design}

We conducted a cost-benefit analysis of outsourcing cleaning services at Mahalapye Hospital to provide information to hospital managers on cost and quality of outsourcing nonclinical services. We selected Mahalapye Hospital as the case study because it only recently began outsourcing cleaning, laundry, and security services, and thus could provide costing information for both insourcing and outsourcing these services. We analysed cleaning services because the data available on the costs and production units of cleaning were more complete than data on other outsourced services.

The analysis takes the hospital manager's perspective when calculating costs and benefits of outsourcing. The horizon for analysis of this study is five years, which allows the study to capture benefits from outsourcing that may accrue in the medium term, such as improvements of the quality of cleaning. We assume that costs, such as the cost of personnel, equipment, supplies, and utilities, remain constant throughout the five-year analysis period. 
This analysis discounts both the costs and benefits of outsourcing to account for the opportunity costs of money. We selected a 10 percent discount rate based on a review that found that the World Bank and African Development Bank use a discount rate of 10-12 percent for cost-benefit analyses of projects implemented in their member countries. ${ }^{[13]}$

\subsection{Alternatives considered}

\subsubsection{Outsourcing}

Mahalapye Hospital outsourced cleaning services to the private Batswana vendor through a three-year contract valued at BWP 18 million (US\$ 1.93 million). Under the outsourcing contract, the vendor provides cleaning staff and all equipment and supplies needed to clean the hospital's floors, windows, walls, doors, ceilings, equipment, and furnishings, and to remove trash. The vendor mixes and stores all hazardous chemicals at its central storeroom. Hospital management oversees the vendor's work and monitors its performance, but is no longer responsible for directly managing the cleaning staff.

\subsubsection{Insourcing}

Before outsourcing cleaning services, Mahalapye Hospital employed and trained its own cleaning staff, purchased supplies, maintained the necessary equipment, and managed the cleaning process in-house. The hospital employed 75 cleaners and orderlies, purchased supplies such as soap, toilet paper, garbage bags, and cleaning chemicals, and maintained vacuums, mops, a polishing machine, and other equipment. The hospital cleaning staff was responsible for cleaning and maintaining the same areas that are currently covered by the outsourcing contract.

In an interview of Mahalapye Hospital management, respondents indicated that, when the hospital was insourcing cleaning, cleaning staff were well trained, but their number was insufficient to clean the hospital to the management's standards. The staffing shortage interfered with the cleaners' ability to adhere to standard hospital operating procedures, adhere to cleaning schedules, maintain a proper store of cleaning supplies, and provide timely management reports on inventory supply, cost, and breakdowns of the equipment. Some of these challenges led the hospital to consider outsourcing to improve the quality and efficiency of cleaning services.

\subsection{Data collection}

Data collectors visited Mahalapye Hospital for five days in October 2014 to collect costing data on insourcing using an Excel-based Auxiliary Services Costing Tool. ${ }^{[14]}$ For missing data, the team sourced commercial equivalent costs, and made assumptions based on available information. A further explanation of the data collection process for insourcing is available. $^{[14]}$

Costing data on outsourcing services was collected during a visit to Botswana in early 2014. Team members surveyed the Chief Economist of the Outsourcing/Public-Private Partnership Unit of the MoH's Office of Strategy Management, to collect data on the value, length, effective dates, and parties of outsourcing contracts signed by Mahalapye Hospital. Interviews of hospital management were conducted in January 2014 and March 2015 to gather information on the contract specifications, vendors, and the services that were included in the outsourcing contracts.

Information on the quality of services was collected in March 2015 using a structured survey of Mahalapye Hospital management. The survey asked the hospital management team to rate the overall quality of hospital services before and after outsourcing using a 10-point Likert scale. The sevenmember management team included the hospital manager, hospital superintendent, chief administration officer, nursing superintendent, chief nursing officer, assistant domestic and laundry officer, and infection control officer. The team was asked 14 open-ended questions about the status of cleaning services in the hospital and how they compared to cleaning services before outsourcing. The surveyors also asked the team to discuss and reach consensus on a collective rating, from one to ten, of the overall quality of cleaning services before the hospital began outsourcing, and a collective rating of cleaning services since initiating outsourcing. A detailed description and survey instruments are available. ${ }^{[12]}$

\subsection{Cost estimates}

Costing for this analysis was conducted using an activity based approach, whereby all indirect and direct costs of each alternative were identified and quantified with a monetary value. We annualised all costs for comparative purposes. Since all costing data were collected in 2014 BWP, we express prices in 2014 constant BWP and 2014 constant United States dollars.

The only direct cost of outsourcing is the cost of the contract. For Mahalapye Hospital, we calculated the annual cost of the cleaning contract by dividing the total contract cost (BWP 18,000,000) by the duration of the contract (3 years). Although the contract length was three years, we assumed the same value for two additional years. We excluded the costs of negotiating the contract and managing the procurement process because these costs could not be collected.

Indirect costs of outsourcing include training, management of the vendor, and operations. Under outsourcing, the hospital conducted joint infection control training with the vendor. 
We calculated training costs by summing the personnel costs of participants and facilitators for the "infection prevention and control" training session. We then divided these costs by two based on the assumption that Mahalapye Hospital and the vendor each covered 50 percent of the costs. This study assumes that the unit cost of training remained the same before and after outsourcing. We excluded training materials and meals from the costs of training before outsourcing and after outsourcing.

The management and oversight of outsourcing includes assessing the quality of the vendor's work and holding meetings with vendor site manager to review reports and address questions and concerns. We could not collect the costs of managing outsourcing, so we estimated the costs as being half of the management costs of insourcing based on the assumption that hospital staff managing outsourcing has a similar cost structure to those who had managed the hospital's cleaning staff under insourcing, but that under outsourcing hospital no longer need to spend the time to directly manage staff or maintain equipment.

Operating costs include electricity, water, and telephones. The hospital was responsible for these costs before and after outsourcing. Utility use may decrease under outsourcing, but we were not able to collect data on operating costs during outsourcing. Since operating costs only make up 2.8 to 3.5 percent of total cleaning costs and are unlikely to have a major impact on the cost-benefit outcome, we assume that operating costs under outsourcing are the same as under insourcing. Stegman et al. calculated electricity costs by multiplying the unit cost of electricity by the estimated annual electrical usage in kilowatts of a floor polishing machine. ${ }^{[14]}$ Water costs were calculated by multiplying the unit cost of water by the estimated volume of water in litres used for mopping, and telephone costs were estimated using the unit cost of a phone line and the number of lines used by the cleaning department. We assume that the outsourced cleaners use the same quantity of utilities as were used during insourcing.

The costs of insourcing also include personnel, supplies, and equipment. Stegman et al. calculated personnel costs based on salary and benefit ranges of the 46 full-time cleaners and 29 orderlies employed by the hospital, and the estimated time each staff member dedicated to cleaning. ${ }^{[14]}$ The study calculated the cost of supplies using the hospital's records. The unit price of each consumable was multiplied by the amount used per month, and then annualised. Delivery costs were assumed to already be included in the prices. Stegman et al. estimated equipment costs using the prices of comparable equipment available for sale in South Africa, Europe,

Published by Sciedu Press or the United States at the time of data collection. ${ }^{[14]}$ For the few items for which ages were known, a straight-line depreciation rate (purchase value divided by the number of years of useful life) was used to calculate the value of the piece of equipment. Maintenance costs were not included in the costing calculations.

The indirect costs of insourcing include training, management, and operational costs. Stegman ${ }^{[14]}$ calculated training costs using the daily rates of participants and facilitators who had attended a "Cleaning Policies" or "Infection Prevention and Control" training in the previous 12 months. Management costs were calculated using the salaries and benefits of managers directly involved with overseeing the hospital's cleaning staff and the percentage of time these managers devoted to supervising cleaning activities. Finally, the methods for calculating operational costs for insourcing were the same as those described above for calculating operational costs of outsourcing. More-detailed information on the costing of the insourcing alternative is available in Stegman et al.'s benchmark costing study. ${ }^{[14]}$

\subsection{Estimating benefits}

Based on a literature review and survey responses, we determined that the direct benefits from outsourcing cleaning services include cost savings for the hospital in personnel, supplies, equipment, training, and management (because the hospital no longer directly bears these costs), and overall better quality of cleaning services. Other benefits identified include reduced time and effort managing cleaning staff, improved adherence to the hospital's cleaning guidelines, improved availability of supplies and equipment, safer storage practices for dangerous chemicals, increased likelihood of properly mixing cleaning supplies, increased numbers of cleaning staff, and improved collection and transport of domestic waste. ${ }^{[12]}$

The indirect benefits of outsourcing include increased opportunities for the management to gain experience working with the private sector, and the potential reduction in the number of hospital-acquired infections due to improved cleanliness.

According to the literature on cost-benefit analyses, the two most relevant approaches for monetising qualitative benefits include measuring a consumer's willingness to pay for a theoretical service and calculating the cost avoidance resulting from an intervention. ${ }^{[15,16]}$ Willingness to pay is widely used for placing value on health services and environmental conservation. ${ }^{[16-21]}$ In this study, estimating willingness to pay would involve asking a sample of hospital managers for the maximum dollar (or pula) amount they would be willing to pay for a hypothetical increase in the cleanliness of a hospital. 
The monetary value obtained from that survey would be tallied as a benefit of outsourcing cleaning services, assuming that outsourcing resulted in an increase in the quality of the service and thus the cleanliness of the hospital.

Measuring cost avoidance would entail estimating the monetary value of each of the intangible benefits of outsourcing. For example, one could estimate the reduction of accidents and infections resulting from the improved adherence to guidelines and safer storage practices. The monetary values of accidents and infections avoided could then be modelled and included as benefits of outsourcing.

Willingness to pay and cost avoidance approaches were too costly and time-intensive for the scope of this study, and would have required the team to make broad assumptions with limited information. Therefore, we only consider two types of benefits: financial cost savings and overall quality of cleaning services. The cost savings for each cost category are equal to the difference between the cost of that category during insourcing and the cost during outsourcing. Importantly, although the total cost of outsourcing is greater than the total cost of insourcing, outsourcing provides cost savings in each of the individual cost categories. In other words, the cost of the contract is an incremental cost of outsourcing, but outsourcing provides incremental savings in personnel, supplies, equipment, training, and management because the hospital no longer directly bears these costs.

To quantify the differences in quality between outsourcing and insourcing, this analysis weights the costs of each alternative by a "quality factor" and recalculates the financial cost savings as "quality-adjusted" cost savings. By weighting the costs of the alternatives based on observed quality, the price of lower quality services is adjusted to a greater degree than the price of higher-quality services, to reflect the hidden costs of an inferior service.

To calculate the quality factor of each alternative, we analysed the responses from the service quality interview of Mahalapye Hospital management and converted those responses to units that could be applied to the cost of the alternatives. In the surveys, the hospital managers rated the overall quality of the cleaning before and after outsourcing using a scale from 1 to 10 , with 1 being the lowest quality and 10 being the highest. Using this information, we calculated the quality factor for cleaning services at Mahalapye Hospital before and after outsourcing, using the following equation (see Equation 1):

$$
\text { Quality factor }=\frac{10}{\text { Likert Scale Rating }}
$$

The managers rated the overall quality of cleaning services
8 out of 10 on the Likert scale during outsourcing, and 6 out of 10 during insourcing. Therefore, the quality factor of outsourcing is 1.25 and the quality factor of insourcing is 1.67 . To weight the costs of the policy alternatives based on the quality of the cleaning service provided, we multiplied the costs of each alternative by their respective quality factors and produced quality-adjusted costs. Weighting the costs of the alternatives allows managers to assess the value for money of outsourcing as compared to insourcing, taking into account the superior quality of outsourced services. It is important to note that the quality-adjusted costs do not reflect the real financial costs of the alternatives, but rather serve only the purpose of comparing the value for money of outsourcing and insourcing for this analysis (see Equation 2):

$$
\text { Quality }- \text { adjusted costs }=\text { Costs } \times \text { Quality Factor }
$$

After calculating the quality-adjusted costs of each of the alternatives, we were able to calculate the quality-adjusted cost savings by subtracting the quality-adjusted costs of outsourcing from the quality-adjusted costs of insourcing.

\section{RESULTS}

\subsection{Annual costs of outsourcing and insourcing}

During 2014, outsourcing cleaning services in Mahalapye Hospital was more costly than insourcing, with an annual cost of BWP 218.68 (US\$23.49) and BWP 173.45 (US\$ 18.63) per square metre, respectively (see Table 1). The annual cost breakdown of outsourcing and insourcing shows that, with outsourcing, the contract covers the direct costs that the hospital incurred when it was insourcing. However, hospitals need to consider the other costs of outsourcing included in this analysis; for example, costs of facilitating infection control trainings for the vendor, utility costs, and the costs of the salary of a hospital manager who oversees and monitors the vendor's work. These indirect costs may be additional to the contract value.

\subsection{Annual quality-adjusted costs of outsourcing and in- sourcing}

Table 1 compares the costs of outsourcing and insourcing after adjusting for the differences in the service quality delivered through the two alternatives. These costs reflect the hidden costs of poor quality services, which show that it costs more to deliver the same quality of cleanliness when insourcing than when outsourcing. After adjusting for quality, it costs BWP 273.35 (US\$29.36) to clean each square metre of the hospital under outsourcing, while it costs BWP 289.09 (US \$31.05) to clean each square metre of the hospital under

ISSN 1927-6990 E-ISSN 1927-7008 
insourcing.

\subsection{Cost-benefit analysis}

Two cost-benefit analyses of outsourcing are presented below (see Table 2). Without adjusting the costs for the quality of the cleaning service of the two alternatives, the net present value (NPV) of outsourcing over a five-year period is ap- proximately BWP -4.9 million (-US\$ 524,135) and the NPV per square metre of hospital floor space is BWP -171.45 (-US\$ 18.42). This means that the Mahalapye Hospital management will lose BWP 4.9 million (US\$ 524,135) in financial assets over five years by choosing to outsource cleaning services.

Table 1. Comparative annual costs of outsourcing and insourcing

\begin{tabular}{|c|c|c|c|c|c|c|c|}
\hline \multirow{2}{*}{ Cost Category } & & \multicolumn{3}{|c|}{ Alternative I: Outsourcing } & \multicolumn{3}{|c|}{ Alternative 2: Insourcing } \\
\hline & & 2014 BWP & $\begin{array}{l}2014 \text { U.S. } \\
\text { dollars }\end{array}$ & $\begin{array}{l}\text { \% of total } \\
\text { cost }\end{array}$ & 2014 BWP & $\begin{array}{l}2014 \text { U.S. } \\
\text { dollars }\end{array}$ & $\begin{array}{l}\text { \% of total } \\
\text { cost }\end{array}$ \\
\hline \multirow{4}{*}{ Direct Costs } & Contract & $6,000,000$ & 644,468 & $96.4 \%$ & - & - & $0 \%$ \\
\hline & Personnel & - & - & $0 \%$ & $1,319,965$ & 141,779 & $26.7 \%$ \\
\hline & Supplies & - & - & $0 \%$ & $2,562,555$ & 275,248 & $51.9 \%$ \\
\hline & Equipment & - & - & $0 \%$ & 769,687 & 82,673 & $15.6 \%$ \\
\hline \multirow{3}{*}{ Indirect Costs } & Training & 4,659 & 500 & $0.1 \%$ & 18,514 & 1,989 & $0.4 \%$ \\
\hline & Management & 46,685 & 5,015 & $0.8 \%$ & 93,371 & 10,029 & $1.9 \%$ \\
\hline & Operational & 172,575 & 18,537 & $2.8 \%$ & 172,575 & 18,537 & $3.5 \%$ \\
\hline \multicolumn{2}{|l|}{ Total } & $6,223,919$ & 668,520 & $100 \%$ & $4,936,668$ & 530,254 & $100 \%$ \\
\hline \multicolumn{2}{|c|}{ Total per square metre (not quality-adjusted) } & 218.68 & 23.49 & - & 173.45 & 18.63 & - \\
\hline \multicolumn{2}{|c|}{ Total per square metre (quality-adjusted) } & 273.35 & 29.36 & - & 289.09 & 31.05 & - \\
\hline
\end{tabular}

Table 2. Cost-benefit analysis of outsourcing for analysis period without adjusting for quality vs. quality-adjusted, 2014 BWP

\begin{tabular}{|c|c|c|c|c|c|c|c|c|c|c|c|c|}
\hline \multirow{2}{*}{ Year } & \multicolumn{6}{|c|}{ Non-quality adjusted } & \multicolumn{6}{|c|}{ Quality-adjusted } \\
\hline & 1 & 2 & 3 & 4 & 5 & Total & 1 & 2 & 3 & 4 & 5 & Total \\
\hline \multicolumn{13}{|l|}{ Tangible Benefits } \\
\hline $\begin{array}{l}\text { Cost savings, } \\
\text { personnel }\end{array}$ & $1,199,968$ & $1,090,880$ & 991,709 & 901,554 & 819,595 & $5,003,707$ & $1,999,947$ & $1,818,134$ & $1,652,849$ & $1,502,590$ & $1,365,991$ & $8,339,511$ \\
\hline $\begin{array}{l}\text { Cost savings, } \\
\text { supplies }\end{array}$ & 2,329,595 & $2,117,814$ & $1,925,285$ & $1,750,260$ & $1,591,145$ & $9,714,100$ & $3,882,659$ & $3,529,690$ & $3,208,809$ & 2,917,099 & $2,651,908$ & $16,190,166$ \\
\hline $\begin{array}{l}\text { Cost savings, } \\
\text { equipment }\end{array}$ & 699,716 & 636,105 & 578,277 & 525,707 & 477,915 & $2,917,720$ & $1,166,193$ & $1,060,175$ & 963,796 & 876,178 & 796,525 & $4,862,867$ \\
\hline $\begin{array}{l}\text { Cost savings, } \\
\text { training }\end{array}$ & 12,596 & 11,451 & 10,410 & 9,464 & 8,603 & 52,524 & 22,758 & 20,689 & 18,808 & 17,098 & 15,544 & 94,898 \\
\hline $\begin{array}{l}\text { Cost savings, } \\
\text { management }\end{array}$ & 42,441 & 38,583 & 35,075 & 31,887 & 28,988 & 176,975 & 88,419 & 80,381 & 73,074 & 66,431 & 60,392 & 368,697 \\
\hline $\begin{array}{l}\text { Cost savings, } \\
\text { operational }\end{array}$ & - & - & - & - & - & & 65,369 & 59,427 & 54,024 & 49,113 & 44,648 & 272,582 \\
\hline Total benefits & $4,284,317$ & $3,894,834$ & $3,540,758$ & $3,218,871$ & $2,926,246$ & $17,865,025$ & $7,225,346$ & $6,568,496$ & $5,971,360$ & $5,428,509$ & 4,935,009 & $30,128,721$ \\
\hline Contract costs & $5,454,545$ & $4,958,678$ & $4,507,889$ & $4,098,081$ & $3,725,528$ & $22,744,721$ & $6,818,182$ & $6,198,347$ & $5,634,861$ & $5,122,601$ & $4,656,910$ & $28,430,901$ \\
\hline Total costs & $5,454,545$ & $4,958,678$ & $4,507,889$ & $4,098,081$ & $3,725,528$ & $22,744,721$ & $6,818,182$ & $6,198,347$ & $5,634,861$ & $5,122,601$ & $4,656,910$ & $28,430,901$ \\
\hline \multicolumn{13}{|l|}{ Cost-Benefit } \\
\hline Net benefits/costs & $-1,170,229$ & $-1,063,844$ & $-967,131$ & $-879,210$ & $-799,282$ & $-4,879,696$ & 407,164 & 370,149 & 336,499 & 305,908 & 278,099 & $1,697,820$ \\
\hline $\begin{array}{l}\text { Net benefits/costs } \\
\text { per square metre }\end{array}$ & -41.12 & -37.38 & -33.98 & -30.89 & -28.08 & -171.45 & 14.31 & 13.01 & 11.82 & 10.75 & 9.77 & 59.65 \\
\hline
\end{tabular}

The cost-benefit analysis of outsourcing after taking into account differences in quality between the two alternatives shows the NPV over the five-year analysis period is BWP $1,697,820$ (US\$ 182,365) and the NPV per square metre of hospital floor space is BWP 59.65 (US\$ 6.41). We estimated the benefit to cost ratio by dividing the discounted

Published by Sciedu Press

benefits (quality-adjusted cost savings) of BWP 30,128,721 (US\$ 3,236,168) of outsourcing by the discounted costs of outsourcing of BWP $28,430,901$ (US\$ 3,053,802) for the fiveyear analysis period. The benefit-cost ratio of 1.06 means that after considering improved quality of cleaning, outsourcing would return approximately six cents in value for every dollar 
invested, and that the hospital management will gain approximately BWP 1.7 million (US\$ 182,365) in total value over the five-year analysis period. Outsourcing passes the acceptability test of net returns/expenditures (BWP 1,697,820/BWP $28,430,901=0.060)>0$. Therefore, outsourcing cleaning services in Mahalapye Hospital provides greater value for money in terms of "cleanliness per pula spent".

\subsection{Sensitivity analysis}

We conducted a sensitivity analysis to test the impact of alternative assumptions on the results of the analysis. Two key assumptions in this analysis include the discount rate and the indirect costs of outsourcing (operations, training, and management). This study also monetises the benefits derived from increased quality of cleaning services using responses to a survey of managers from Mahalapye Hospital. We conducted a sensitivity analysis to demonstrate the effect of increasing and decreasing the costs of operations, training, and management each by 20 percent, increasing and decreasing the discount rate by 20 percent (from 10 in the base case to 8 and to 12), and increasing and decreasing the managers' service quality rating of outsourced services by 20 percent (from 8 in the base case to 6.4 and 9.6) on the quality-adjusted NPV of outsourcing. The impacts of varying the contract costs by 20 percent are also plotted on the tornado diagram for comparative purposes (see Figure 1).

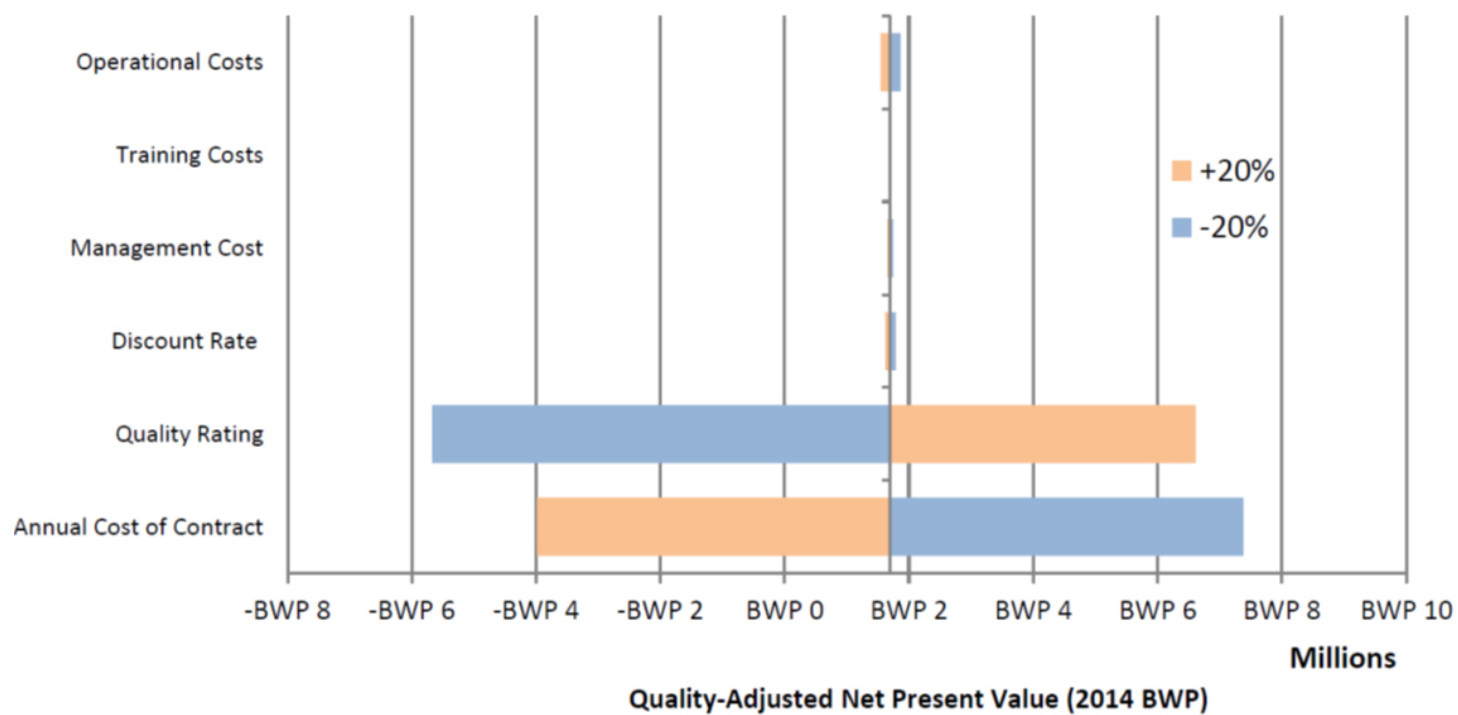

Figure 1. Sensitivity analysis to assess the impact of our main assumptions on the NPV of outsourcing

Figure 1 shows that training, operating and management costs as well as the discount rate, have relatively little impact on the quality-adjusted NPV of outsourcing. Increasing the cost of training by 20 percent (from BWP 4,658.56 to BWP 5,590.56) decreases the NPV of outsourcing from BWP $1,697,820$ to BWP $1,693,405$. A 20 percent increase in operating costs would reduce the NPV from BWP 1,697,820 to BWP 1,534,271. Finally, increasing the management costs from BWP 46,685 to BWP 56,022 would reduce the qualityadjusted NPV from $1,697,820$ to $1,653,576$. The NPV is positive for all scenarios where these assumptions are varied by 20 percent, meaning that outsourcing would still be cost beneficial. On the other hand, the value for money of outsourcing is highly dependent on the rating of the quality of cleaning services since outsourcing. An increase of 1.6 points in the perceived quality on the Likert scale (from 8 to 9.6) produces an increase of approximately BWP 4.9 million in the value for money of outsourcing, while a decrease in 1.6 points on the Likert scale (from 8 to 6.4) produces a decrease in NPV of approximately BWP 7.4 million. These results demonstrate the importance of monitoring the quality of outsourced services. Varying the cost of the contract also has a significant impact on the quality-adjusted NPV of outsourcing. Increasing the cost of the contract by 20 percent decreases the quality-adjusted NPV by approximately BWP 5.7 million, while decreasing the cost of the contract by 20 percent increases the quality-adjusted NPV by approximately BWP 5.7 million. Additionally, we determined that outsourcing would still be cost-beneficial with a five percent increase from the base case cost (BWP 210.82 [US\$22.64] per square metre per year) of the contract. We estimated threshold prices for the outsourcing contracts: the price of a contract at which the change would be cost neutral for the hospital manager was estimated at BWP 221.57 (US\$23.80) 
per square-metre per year. In other words, outsourcing cleaning services would no longer be cost-beneficial if contract costs were increased by 5.1 percent above the current cost, holding other variables constant.

\section{Discussion}

We assessed the cost-benefit analysis of outsourcing cleaning services as compared to producing those same services in-house at Mahalapye Hospital and found outsourcing to be more costly, but also found that outsourcing provides a greater value for money to hospital managers because it has resulted in a significant observed increase in the quality of cleaning services. Our analysis also reveals several key lessons for hospital managers who are exploring the possibility of outsourcing or preparing to negotiate outsourcing contracts with vendors.

\subsection{Assessing the value of outsourcing and making in- formed decisions requires detailed information on the status quo}

Hospital managers need to collect costing and production data from insourcing, in order to assess the potential value for money of outsourcing nonclinical services, evaluate bids from private vendors, and engage in effective contract negotiation with vendors. This study demonstrates the importance of collecting accurate data on staff salaries, benefits, and time worked, the unit price and rate of consumption of supplies, the unit price, age, and maintenance costs of equipment, the personnel costs of training facilitators and participants, the personnel costs of management, and the unit price and amount of utilities consumed by the service to be outsourced.

It is equally important for hospitals to collect data on the production units of the services they wish to outsource, as this information is crucial for comparing vendors' bids with the cost of providing a service in-house. For example, hospital managers need to know the hospital's floor area (usually in square metres) to compare costs of cleaning services. Without this information, hospital managers cannot determine the unit cost of providing services in-house, and therefore will not know whether they are getting a fair offer from vendors, nor whether vendors are making realistic promises that they will be able to uphold.

Hospital managers should evaluate the effort and resources that would be required to build the capacity of in-house cleaning services. This would allow managers to assess whether outsourcing or strengthening insourcing would be a better investment for improving the quality of cleaning services.

Published by Sciedu Press

\subsection{Outsourcing can be more costly than insourcing}

Botswana's privatisation strategy is based on the premise that outsourcing public services to private companies will allow the delivery of higher-quality services at a lower cost. The results of this analysis show that outsourcing can be more costly than providing a service in-house. A quick comparison of the costs of outsourcing and insourcing cleaning services at Mahalapye Hospital shows that the annual cost of the outsourcing contract (BWP 6.0 million) is approximately BWP 1.1 million more than the annual cost of insourcing (BWP 4.9 million). Hospital managers also need to consider the costs above and beyond the contract cost that they will continue to incur after switching to outsourcing. Under outsourcing, Mahalapye Hospital continues to provide infection-control training for the external cleaning staff, pay all utility costs, and spend significant amounts of time and money managing the vendor. After tallying all tangible costs, the annual costs of outsourcing exceed the costs of insourcing by approximately BWP 1.3 million (US\$ 140,000). In order to make an accurate cost projection of outsourcing, hospitals should ensure during negotiations that the contract defines exactly what each party is responsible for providing. Finally, managers should consider the intangible costs of outsourcing, including decreased knowledge of infection control policies among cleaning staff, increased staff turnover, potentially worse relations with labour unions, and the continued need for hospital management and supervision of the vendor. These intangible costs have the potential to result in significant financial loss to the hospital.

\subsection{Benefits are just as important as costs for decision- making}

Hospital managers should not make decisions based solely on the cost of outsourcing, but rather on the value for money of outsourcing. Even if outsourcing is more costly than providing a service in house, it may still be justified if it delivers a significant increase in the level of quality of the service. When we analysed the cost-benefit of outsourcing cleaning services in Mahalapye without taking into account quality, outsourcing appeared to not be cost-beneficial. After adjusting for the improvement in quality, we found that outsourcing delivered a higher value for money.

To justify paying more for a better service, however, hospitals must commit to vigorously monitoring the quality of services provided by private vendors, and hold them accountable for their quality. Managers must define quality standards during the contract negotiation phase to ensure that both parties have the same expectations of what constitutes quality services. Hospital managers should then monitor key performance indicators as contracted in the service level agreement and 
conduct regular quality assessments together with vendor managers to ensure that expectations are being met.

It is also important for hospitals to consider other benefits of outsourcing in addition to improved quality, such as improved adherence to guidelines, improved availability of supplies, safer chemical storage and mixing practices, improved waste collection, possible reduction in hospital-acquired infections due to safer practices and increased cleanliness, and more experience collaborating with the private sector. These intangible benefits may result in financial savings for the hospital or better health outcomes, both of which may justify the higher up-front financial costs of outsourcing.

\subsection{Hospitals and vendors could both gain from closer collaboration}

Closer collaboration between hospitals and vendors through sharing information, joint quality monitoring, and joint training could lower the costs and increase the benefits of outsourcing for hospital management. This study focuses on the need for hospitals to collect more data on insourcing, and conduct more thorough analysis of the potential costs and benefits of outsourcing, but vendors could also gain from more information and analysis. Vendors that are used to working in non-clinical settings often know little about the costs of providing services in hospitals, and thus could mistakenly offer to provide these services for a fee that does not cover their full costs. Underbidding is especially likely among young companies without much experience operating in hospitals. Hospitals wishing to outsource could build trust with vendors by sharing information on the current costs of providing the service in-house, and giving them a base price upon which to make their bid. When both parties negotiate in the dark, one will likely get a raw deal at the expense of the other. If both parties negotiate with full information, it will be easier to agree on a fair price that is satisfactory to both the hospital and the vendor. Sharing costing information during contract negotiations could help hospital managers to establish a strong working relationship with vendors, which will facilitate cooperation on other issues for the duration of the contract.

Quality monitoring is another potential area for collaboration between hospital management and vendors. Both parties have an interest in ensuring that the services are delivered at the highest possible quality: in addition to ensuring patient care and safety, hospitals want the greatest value for money, while vendors want to develop a reputation as a high-quality brand and secure future business. Approaching quality assurance in a collaborative rather than confrontational manner could result in better quality outcomes. Joint "walk-abouts" where managers from both parties assess the quality of ser- vices together are one possible approach. ${ }^{[12]}$

Many private companies in Botswana have little or no prior experience operating in hospitals, and are unfamiliar with the unique decontamination requirements and safety protocols of the health sector. Joint training sessions, where hospital staff teaches infection control practices to the vendor's cleaning staff could increase the capacity of private vendors, while improving the quality of the service provided to the hospital.

\subsection{The costs and benefits of outsourcing should im- prove over time}

Hospitals should reassess the costs and benefits of outsourcing periodically, as they are likely to improve as vendors and hospital managers gain experience with the outsourcing process. Vendors may be able to provide better-quality services at lower costs as they increase operational efficiency, incorporate innovations in management and service provision methodologies, and increase their economies of scale. Hospitals may improve their ability to negotiate lower prices, and could get better deals as they develop long-term, trusting relationships with vendors. The quality of services could also improve as hospitals increase their capacity to monitor vendors and enforce adherence to quality standards.

\subsection{Limitations}

Our study has some limitations: for example, the quantification of the benefits of outsourcing is highly dependent on the results of one collective survey response of Mahalapye's management team, which reported an observed increase in quality of cleaning services of 2 points on the Likert scale after outsourcing. Despite this limitation, the management team's assessment of the improvement in quality of cleaning services after outsourcing is supported by evidence from other surveys of managers and nurses with knowledge of outsourcing efforts at Mahalapye and other public hospitals in Botswana. In a 2015 survey of 14 nurses at Mahalapye Hospital, 69 percent responded that the overall quality of cleaning services at the hospital had improved since outsourcing. The Mahalapye managers' assessment of the improved quality of outsourcing services is also consistent with observations made at six other public hospitals in Botswana that have already begun outsourcing. Surveys of the management teams at seven hospitals demonstrated an average improvement in observed quality of cleaning of 2.7 points on the Likert scale after outsourcing (compared to 2 points in Mahalapye Hospital). The managers' rating of cleaning services increased from an average of 4.85 before outsourcing to 7.57 after outsourcing across the seven hospitals, which is similar to the increase from 6 before outsourcing to 8 after outsourcing reported at Mahalapye. Furthermore, the observed increase 
in quality from outsourcing was consistent across several other non-clinical services: the quality of security services increased by an average of 2.2 points on the Likert scale and the quality of laundry services increased by an average of 3.6 points. ${ }^{[12]}$ Finally, the management team is exposed to all aspects of the outsourcing experience, including negotiating with the vendor, training cleaning staff, monitoring the cleanliness of all areas of the hospital, and monitoring the incidence of hospital-acquired infections. This makes management staff well-suited to provide an overall assessment of the change in quality of cleaning services due to outsourcing.

Another limitation is that this study does not provide information on the determinants of the increased service quality provided by the vendor. It is possible that insourcing could deliver the same value-for-money as outsourcing if the hospital invested more money into hiring additional cleaners and improving supervision of its own cleaning staff rather than contracting out to a private firm.

The third limitation is the lack of data for some costs. We were unable to acquire the costs of negotiating the contract with the vendor, the proportion of training costs covered by Mahalapye hospital and the vendor, the cost of utilities under outsourcing, or the recurring costs of managing and overseeing the vendor. We excluded the costs of negotiating the contract due to lack of information on the process. We estimated the other costs and varied them in the sensitivity analysis, which showed that these costs have little impact on the final results of the study.

Finally, the study does not consider possible cost reductions throughout the five year analysis period from learning and technological change. If the vendor reduces its costs through learning and passes them on to the hospital in the form of cheaper future contracts, outsourcing would be slightly more cost-beneficial.

\section{Conclusions}

This study fills an important gap in the literature surrounding the cost-benefit of outsourcing of non-clinical services in developing countries. Through the case study at Mahalapye Hospital, we show that, while more costly, outsourcing resulted in increased quality of cleaning services, and greater value for money. The results and lessons learned from this study are crucial for other governments and industries that are weighing the pros and cons of outsourcing or are negotiating contracts with vendors. More such studies should be conducted in Africa and other developing regions to help hospital managers make evidence-based outsourcing decisions.

Outsourcing is a powerful tool to improve hospital service delivery and hospital efficiency, which ultimately improves health system performance. The concept of outsourcing is not new and a growing number of governments are choosing to outsource, allocating significant portions of their budgets to contracting-out the provision of public goods and services. As more and more developing countries choose to outsource hospital services, it is critical that they get the outsourcing agreements "right". As we have shown, outsourcing requires sound benchmark data and proper quality monitoring in order to succeed - only then can it achieve the objective of improving service delivery, increasing efficiency and strengthening overall health system performance.

\section{ACKNOWLEDGEMENTS}

The authors thank the hospital staff at Mahalapye Hospital for their invaluable help and input in supplying data and feedback on the outsourcing initiative. We also thank the hospital staff at S'brana Psychiatric Hospital, Sekgoma Memorial Hospital, Nyangabgwe Referral Hospital, Princess Marina Hospital, Letsholathebe II Memorial Hospital, and Scottish Livingstone Hospital for their cooperation in providing key input and feedback on the outsourcing initiative.

We thank Ndwapi Ndwapi, Naz Todini, Louise Myers, Marsha Slater, Peter Stegman, Ben Johns and Steve Musau for their invaluable input during all of the stages of the development of this study.

\section{CONFLicts OF INTEREST Disclosure}

We declare that none of the competing interests found at http://www.icmje.org/index.html\# are relevant and therefore have nothing to declare. The work was done independently of influence from funding.

\section{Disclaimer}

The views and opinions expressed in this article are those of the authors and do not necessarily reflect the official policy or position of USAID. USAID provided funding for this study.

\section{REFERENCES}

[1] International Monetary Fund. World Economic Outlook 2014. Washington, DC: IMF; 2014. Accessed on the IMF website 23/03/2015. Available from: http://www.imf .org/external/ns/cs . aspx?

Published by Sciedu Press id $=29$

[2] Ministry of Finance and Development Planning. Privatisation Master Plan. Gaborone, Botswana; 2005.

[3] Liu X, Hotchkiss DR, Bose S, et al. Contracting for Primary Health 
Services: Evidence on Its Effects and Framework for Evaluation. Bethesda, MD: Abt Associates; 2004.

[4] Loevinsohn B, Harding A. Buying Results? Contracting for Health Service Delivery in Developing Countries. The Lancet. 2005; 366(9486): 676-681. http://dx.doi.org/10.1016/S0140-673 6(05) 67140-1

[5] Siddiqi S, Masud TI, Sabri B. Contracting But Not without Caution: Experience with Outsourcing of Health Services in Countries of the Eastern Mediterranean Region [Research Support, Non-U.S. Gov't]. Bulletin of the World Health Organization. 2006; 84(11): 867-875. PMid: 17143460.

[6] Mills A, Broomberg J. Experiences of Contracting Health Services: An Overview of the Literature. Health Economics \& Financing Programme. 1998; 60.

[7] Mills A. To Contract or Not To Contract? Issues for Low and Middle Income Countries. Health Policy Plan. 1998; 13(1): 32-40. PMid: 10178183. http://dx.doi.org/10.1093/heapol/13.1.32

[8] Patouillard E, Goodman CA, Hanson KG, et al. Can working with the private for-profit sector improve utilization of quality health services by the poor? A systematic review of the literature. Int J Equity Health. 2007; 6: 17. PMid: 17988396. http://dx.doi.org/10.1186/1 475-9276-6-17

[9] Corby N, Nunn M, Welch K. Addressing the Need: Lessons for Service Delivery Organizations on Delivering Contracted-Out Family Planning and Reproductive Health Services I Primer. Bethesda: Abt Associates; 2012.

[10] Private Sector Partnerships One. Primer for PolicymakersContracting-out Reproductive and Family Planning Services: Contracting Management and Operations. May 2006. Retrieved April 15, 2015. Available from: https://www.k4health.org/sites/def ault/files/Primer\%20for\%20policymakers.pdf

[11] Perrot J. The Role of Contracting in Improving Health Systems Performance. Geneva: World Health Organization; 2004. 62.

[12] Cogswell H, Buzwani M, Myers L, et al. Experiences in Outsourcing Nonclinical Services among Public Hospitals in Botswana. Bethesda,
MD: Health Finance and Governance Project, Abt Associates; April 2015.

[13] Asian Development Bank. Cost-Benefit Analysis for Development: A Practical Guide. Mandaluyong City, Philippines: Asian Development Bank. 2013. Available from: http://www.adb.org/documents/ cost-benefit-analysis-development-practical-guide

[14] Stegman P, Ohadi E, Buzwani M, et al. Benchmarking Costs for NonClinical Services in Botswana's Public Hospitals. Bethesda, MD: Health Finance \& Governance Project, Abt Associates; 2015.

[15] Cellini SR, Kee JE. Cost-Effectiveness and Cost-Benefit Analysis. In Handbook of Practical Program Evaluation, ed. Wholey JS, Hatry HP, and Newcomer KE. San Francisco, CA: Jossey-Bass; 2010. 493-530.

[16] Olsen JA, Smith RD. Theory Versus Practice: A Review of 'Willingness-To-Pay' in Health and Health Care. Health Econ. 2001; 10: 39-52. http://dx.doi.org/10.1002/1099-1050(200101 ) $10: 1<39:$ :AID-HEC563>3.0.CO;2-E

[17] Diener A, O'Brien B, Gafni A. Health Care Contingent Valuation Studies: A Review and Classification of the Literature. Health Economics. 1998; 7: 313-326. http://dx.doi.org/10.1002/(SICI ) 1099-1050 (199806) $7: 4<313:$ :AID-HEC350>3.0.CO;2-B

[18] Klose T. The Contingent Valuation Method in Health Care. Health Policy. 1999; 47: 97-123. http://dx.doi.org/10.1016/S0168 -8510 (99) 00010-X

[19] Smith RD. Construction of the Contingent Valuation Market in Health Care: A Critical Assessment. Health Econ. 2003; 12: 609-628. PMid: 12898660. http://dx.doi.org/10.1002/hec. 755

[20] Fang H, Yang Z, Wang H, et al. Estimating Willingness to Pay for Environment Conservation: A Contingent Valuation Study of Kanas Nature Reserve, Xinjiang, China. Environ Monit Assess. 2011; 180(14): 451-9. PMid: 21107901. http://dx.doi.org/10.1007/s10 661-010-1798-4

[21] Israel D, Levinson A. Willingness to Pay for Environmental Quality: Testable Empirical Implications of the Growth and Environment Literature. The B.E. Journal of Economic Analysis \& Policy. 2004; 3(1): 1-31. http://dx.doi.org/10.2202/1538-0645.1254 